\title{
Reactivation of occult HBV infection in an HIV/HCV Co-infected patient successfully treated with sofosbuvir/ledipasvir: a case report and review of the literature
}

Gabriele Fabbri", Ilaria Mastrorosa, Alessandra Vergori, Valentina Mazzotta, Carmela Pinnetti, Susanna Grisetti, Mauro Zaccarelli, Adriana Ammassari and Andrea Antinori

\begin{abstract}
Background: Reactivation of occult or inactive Hepatitis B virus (HBV) infection during immunosuppressant treatments is well known and widely described in literature. The same observation has been made in Hepatitis $C$ (HCV)-infected patients previously exposed to HBV and treated with interferon-free DAA treatments. Because of common transmission routes, persons may have been exposed to HCV, HBV and HIV, but few cases have been reported in this scenario to date. Frequency of HBV reactivation in HIV/HCV co-infected patients previously exposed to HBV and treated with DAA remains unclear. Herein, we report an episode of HBV reactivation in an HIV/HCV co-infected patient prescribed with sofosbuvir/ledipasvir for HCV.
\end{abstract}

Case presentation: The patient is a Caucasian 54-years old female, with HIV/HCV co-infection (genotype 4), and a previous exposure to HBV, documented by negativity of $\mathrm{HBsAg}$ and positivity of $\mathrm{HBsAb}$ and $\mathrm{HBCAb}$. Her medical history included: myocardial infarct, chronic kidney disease stage 3, chronic obstructive pulmonary disease, and mild pulmonary hypertension. HCV had not been treated with interferon (IFN)-based regimens and liver stiffness was 10. $5 \mathrm{KPa}$ (Metavir stage F3) at hepatic elastography. Because of CKD, she was prescribed with a nucleoside reverse transcriptase (NRTI)-sparing regimen including darunavir/ritonavir plus etravirine, and thereafter with sofosbuvir/ ledipasvir for 12 weeks. Four weeks after DAA termination, the patient was hospitalized with symptoms of acute hepatitis. Blood tests showed HCV RNA $<12 \mathrm{IU} / \mathrm{ml}$, but positivity of HBAg, HBeAg, and of anti-core antibodies (IgM and $\lg \mathrm{G}$ ), while anti-HBs and anti-HBe antibodies were negative. HBV DNA was $6.06 \mathrm{Log}_{10} \mathrm{IU} / \mathrm{ml}$. Entecavir was started obtaining resolution of symptoms, normalization of liver enzymes, as well as reduction of HBV DNA and of quantitative HBV surface antigen.

Conclusions: This case-report highlights the risk of HBV reactivation with interferon-free DAA treatment in HIV/HCV co-infected patients previously exposed to HBV and who have contraindications for treatment with nucleoside/ nucleotide reverse transcriptase Inhibitors because of comorbid conditions. In the setting of HIV infection, clinicians prescribing DAA should be aware of this risk, and HBV assessment at treatment start as well as virological monitoring during DAA treatment is recommended. Large epidemiological and virological studies are needed to investigate reactivation of occult HBV infection more in depth.

Keywords: Acute hepatitis, Sofosbuvir/ledipasvir, HBV reactivation, HIV, DAA

* Correspondence: gabriele.fabbri@inmi.it

National Institute of Infectious Diseases "Lazzaro Spallanzani", Via Portuense 292, 00152 Rome, Italy 


\section{Background}

Reactivation of HBV infection during immunosuppressant treatments is well known and widely described in literature [1]. The risk concerns subjects with occult HBV infection (HBV DNA detected in serum or in the liver in HBsAg-negative patients with or without serologic markers of previous viral exposure) or inactive HBV chronic carriers (HBsAg-positive with normal ALT and HBV DNA $\left.<3.30 \log _{10} \mathrm{IU} / \mathrm{ml}\right)$, either undergoing transplant or treated with chemotherapy or immunosuppressant drugs for hematologic malignancies or rheumatologic disorders [2].

In the past, with the use of interferon (IFN)-based $\mathrm{HCV}$ therapy, exacerbation of acute HBV hepatitis in HBV-exposed patients has been described and an immune modulating role of IFN postulated [3]. More recently, a similar observation has been made with the use of interferon-free directly acting antivirals (DAA) for $\mathrm{HCV}$ treatment [4]. In HIV/HCV co-infected patients, who show HCV cure rates comparable to the general population [5], only very few cases of $\mathrm{HBV}$ reactivation have been reported [6-10]. Thus, the frequency of HBV reactivation in $\mathrm{HIV} / \mathrm{HCV}$ co-infected patients previously exposed to HBV and treated with DAA remains unclear.

Herein, we report an episode of reactivation of occult $\mathrm{HBV}$ infection in an $\mathrm{HIV} / \mathrm{HCV}$ co-infected patient prescribed with sofosbuvir/ledipasvir for $\mathrm{HCV}$ treatment. Further, a short review of similar cases published in literature is outlined.

\section{Case presentation}

The patient is a Caucasian 54-years old female diagnosed with HIV in 1986 and with chronic HCV hepatitis (genotype 4) in 1992. For many years, she was lost to follow-up and refused antiretroviral therapy presenting only once in 2011, when blood tests showed HIV RNA $4.93 \log _{10}$ IU/ ml, CD4 cells 245/mmc. Concurrently, previous exposure to $\mathrm{HBV}$ infection was documented: $12.2 \mathrm{mIU} / \mathrm{ml} \mathrm{HBsAb}$ (positive $>10 \mathrm{mIU} / \mathrm{ml}$ ), positive $\mathrm{HBcAb}$, and negative $\mathrm{HBsAg}$ at $0.01 \mathrm{IU} / \mathrm{ml}$ (positive $>0.05 \mathrm{IU} / \mathrm{ml}$ ). Afterwards she showed up again in June 2015, when viroimmunological exams showed: HIV RNA $5.28 \log _{10}$ copies/ml and CD4 count $218 / \mathrm{mmc}$. At that time, her medical history included: myocardial infarct, chronic kidney disease (CKD) stage 3 , chronic obstructive pulmonary disease, and mild pulmonary hypertension. HCV had not been treated with IFN-based regimens and liver stiffness was $10.5 \mathrm{KPa}$ (Metavir stage F3) at hepatic elastography. Because of CKD, first-line antiretroviral treatment was a nucleoside reverse transcriptase (NRTI)-sparing regimen including darunavir/ritonavir 800/100 mg plus etravirine $400 \mathrm{mg}$ QD. In January 2016, blood tests showed HIV RNA not detected $<40$ copies/ml with CD4 cells $283 / \mathrm{mmc}$ and treatment with sofosbuvir/ledipasvir $400 / 90 \mathrm{mg}$ once daily was prescribed for 12 weeks. In May 2016, four weeks after treatment completion, the patient presented with jaundice reporting vomiting, nausea, and abdominal pain. She was admitted to hospital, and an elevation of liver enzymes (ALT $435 \mathrm{IU} / \mathrm{l}$ and AST $410 \mathrm{IU} / \mathrm{l}$, respectively) and total bilirubin at $7.1 \mathrm{mg} / \mathrm{dl}$ were documented. HCV RNA was $<12$ IU/ml, HIV RNA <40 copies/ml and CD4 count had increased to $561 / \mathrm{mmc}$. With regards to $\mathrm{HBV}$ markers, $\mathrm{HBsAg}$ (3.71 $\log _{10} \mathrm{IU} / \mathrm{ml}$ ) and $\mathrm{HBeAg}$ changed into positive together with $\operatorname{IgM}$ and IgG $\mathrm{HBcAb}$, while $\mathrm{HBsAb}$ and $\mathrm{HBeAb}$ remained negative. Furthermore, HBV DNA was $6.06 \log _{10} \mathrm{IU} / \mathrm{ml}$. Treatment with entecavir $0.5 \mathrm{mg}$ once daily was promptly started obtaining resolution of symptoms. One month later, blood tests documented normalization of transaminases and reduction of HBV DNA at $3.78 \log _{10} \mathrm{IU} / \mathrm{l}$, of HBsAg $1.91 \log _{10} \mathrm{IU} / \mathrm{ml}$ and negativization of $\mathrm{HBeAg}$ (Fig. 1). Treatment for HBV infection is still ongoing without adverse events and sustained virological response for $\mathrm{HCV}$ was achieved at 12 and at 24 weeks of observation.

\section{Discussion}

HBV reactivation of occult or inactive $\mathrm{HBV}$ infection in $\mathrm{HCV}$-infected persons during or after DAA therapy is considered a rare event, even though lately an important warning by the FDA about 24 cases of HBV reactivation during DAA HCV treatment has been released [11]. In literature to date, only six cases of these have been reported and characteristics are summarized in Table 1: all events occurred in subjects aged 50 years or more, mostly infected by HCV genotype 1, with frequent previous IFN exposure, and treated with sofobuvir- or daclatasvir-based DAA regimens. Notably, only one case referred to a person with HIV co-infection. Occasionally HBV reactivation occurred during DAA treatment, while otherwise it developed after treatment completion. In some cases, diagnosis was retrospectively established.

To date, risk of $\mathrm{HBV}$ reactivation during treatment with ledipasvir/sofosbuvir seems low, and our patient is only the second case described in literature [7]. Regarding frequency of the event, reassuring data are available from a recent study by Sulkowski et al., which retrospectively reanalyzed HBV markers in serum samples of $173 \mathrm{HCV}$-infected patients without active HBV or HIV infection and treated with a combination of ledipasvir/ sofosbuvir. Notably, HBV reactivation during or after HCV clearance was found in none out of the 103 previously HBV-exposed patients [12]. Differently, in patients with $\mathrm{HCV}$ and HBV co-infection, transitory HBV DNA reactivation rate seems very high, reaching $88 \%$ of a small case series treated with ledipasvir/sofosbuvir [13]. Since accurate information regarding risk of $\mathrm{HBV}$ reactivation in patients undergoing DAA therapy is lacking, an important prospective study is ongoing in patients 


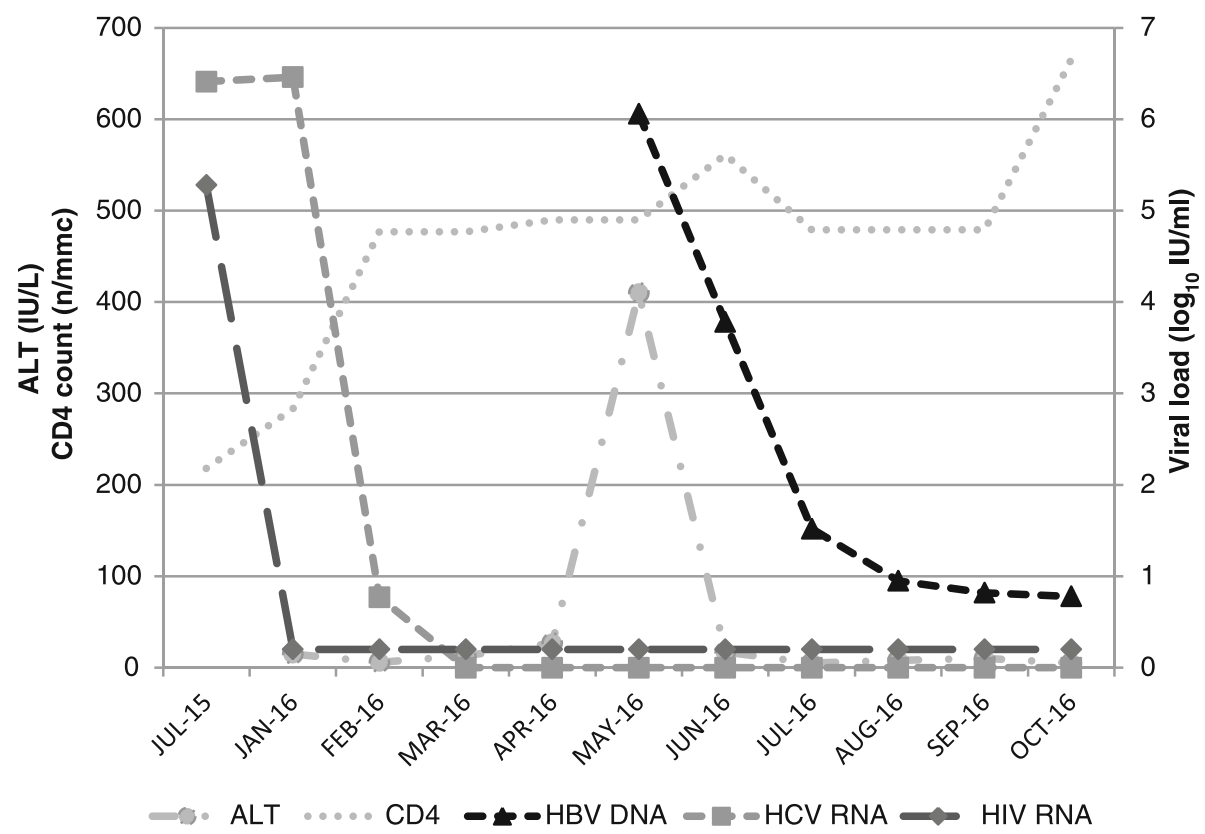

Fig. 1 Plasma HIV, HCV, HBV viral loads, liver function and CD4 cell count depicted over time

with active $\mathrm{HBV} / \mathrm{HCV}$ infection [13], but the issue should also be addressed in $\mathrm{HCV}$-infected patients with occult HBV infection.

In our patient, the rapid clearance of HCV RNA with DAA treatment could have triggered HBV reactivation leading to acute symptomatic hepatitis B. It also should to be noted that, the low levels of HBsAb in 2011 and the absence of this protective marker at hepatitis onset, might have played an important role in allowing HBV reactivation. In fact, our patient was not taking any ARV regimen for 15 years after HIV diagnosis and this has led to marked immunodeficiency: similarly to what happens in patients undergoing allogenic stem cells transplantation, we can assume that she may have lost her immunity against HBV [14].

The molecular mechanisms involved in $\mathrm{HCV} / \mathrm{HBV}$ interferences are controversial and incompletely understood. It seems that HBV can be chronically suppressed by $\mathrm{HCV}$ infection with alternate phases of dominance of one virus on the other $[15,16]$ and a suppressing effect of $\mathrm{HCV}$ core proteins on HBV replication has been postulated in some studies $[17,18]$. Other studies have suggested that, host genes and immune regulation, such as kinase pathways or microRNA pathways, mediate the mechanism of underlying $\operatorname{HBV}$ inhibition $[19,20]$. Regardless of the molecular mechanisms involved in $\mathrm{HCV} / \mathrm{HBV}$ co-infection, the introduction of DAA drugs that are specifically directed against HCV without inhibitory effect on HBV may unbalance viral and/or host interactions and eventually allow HBV reactivation [21].

Our case report poses some further questions, because the patient had HBV reactivation after DAA treatment, but also was HIV-positive making the scenario even more complex. On one side, HIV-infected patients may experience various levels of immune deficiency, because of lower CD4 cell count and immune dysregulation [22], malignancies or rheumatologic diseases. Also immune reconstitution in antiretroviral-treated patients may play

Table 1 Characteristics of patients with HBV reactivation during or after DAA treatment for HCV published in literature

\begin{tabular}{|c|c|c|c|c|c|c|c|c|}
\hline Patient & Ref. & Gender, age & HCV genotype & Previous IFN & DAA treatment & HBV profile & HIV status & Symptoms onset \\
\hline 1 & [7] & $M, 53$ & $4 d$ & Yes & SOF/LDV & Resolved HBV & + & At 6 weeks during DAA \\
\hline 2 & [6] & $M, 55$ & $1 \mathrm{a}$ & Yes & SOF/SMV & Inactive HBV & - & At 8 weeks during DAA \\
\hline 3 & [6] & $M, 57$ & $1 \mathrm{a}$ & Yes & SOF/SMV & Occult HBV & - & At 4 weeks during DAA \\
\hline 4 & [10] & $F, 59$ & $1 b$ & Yes & SOF/SMV/RBV & Resolved HBV & - & At 11 weeks during DAA \\
\hline 5 & [9] & $M, 69$ & $1 b$ & No & DCV/ASV & Inactive HBV & - & At 6 weeks during DAA \\
\hline 6 & [8] & $F, 83$ & $1 b$ & NA & DCV/ASV & NA (HBsAg neg) & - & At 20 weeks after DAA \\
\hline
\end{tabular}

Legend: $M$ male, $F$ female, IFN interferon, RBV ribavirin, SOF sofosbuvir, SMV simeprevir, DCV daclatasvir, ASV asunaprevir, $H B V$ hepatitis $B$ virus, $H C V$ hepatitis $C$ virus, $D A A$ direct antiviral agents, $N A$ not available, neg negative 
a role in the same direction. In fact, reactivation of several latent infections, including HBV infection, is facilitated by immune reconstitution [23], and our patient experienced a relevant increase in CD4 cell count when comparing values before and after DAA treatment. On the contrary however, it is likely that a considerable proportion of patients with HIV infection will receive anti-HBV agents, like lamivudine, emtricitabine or tenofovir, as part of their antiretroviral therapy during DAA therapy, and therefore will be protected from HBV reactivation. Nonetheless, this may not apply to a considerable number of HIV-positive patients, that have contraindications for treatment with nucleoside/nucleotide reverse transcriptase Inhibitors because of comorbid conditions and who receive dual regimens [24].

\section{Conclusions}

In conclusion, this case-report highlights the risk of HBV reactivation with interferon-free DAA treatment in HIV/ $\mathrm{HCV}$ co-infected patients previously exposed to HBV and who have contraindications for treatment with nucleoside/nucleotide reverse transcriptase Inhibitors because of comorbid conditions. In the setting of HIV infection, clinicians prescribing DAA should be aware of this risk, and HBV assessment at treatment start as well as virological monitoring during DAA treatment is recommended. Large epidemiological and virological studies are needed to investigate reactivation of occult $\mathrm{HBV}$ infection more in depth.

\section{Abbreviations}

CKD: chronic kidney disease; DAA: direct antiviral agents; DAA: direct antiviral agents; IFN: interferon; NRTI: nucleoside reverse transcriptase inhibitors

\section{Acknowledgments}

Not applicable.

\section{Funding}

No funding has been used to support this manuscript.

\section{Availability of data and materials}

Data sharing is not applicable to this article, as no datasets were generated or analyzed in the current study.

\section{Authors' contributions \\ GF, IM, AV, VM, AAm and AAn conceived and drafted the manuscript, performed a literarature review and were actively involved in revising it critically. CP, SG, MZ were involved in clinical care of the patient, performed most of serological information about HBV reactivation and revised the manuscript. Each author agreed to be accountable for all aspects of the work. All authors read and approved the final manuscript.}

\section{Competing interest}

The authors declare that they have no competing interests.

\section{Consent for publication}

Written informed consent was obtained from the patient for publication of this Case report and any accompanying images. A copy of the written consent is available for review by the Editor of this journal.
Ethics approval and consent to participate

Not applicable.

Received: 30 November 2016 Accepted: 23 February 2017

Published online: 01 March 2017

\section{References}

1. Sagnelli C, Macera M, Pisaturo M, Zampino R, Coppola M, Sagnelli E. Occult HBV infection in the oncohematological setting. Infection. 2016:44:575-82.

2. Sagnelli E, Pisaturo M, Martini S, Filippini P, Sagnelli C, Coppola N. Clinical impact of occult hepatitis B virus infection in immunosuppressed patients. World J Hepatol. 2014;6:384-93.

3. Potthoff A, Berg T, Wedemeyer H, HEP-NET B/C Coinfection Study Group. Late hepatitis B virus relapse in patients co-infected with hepatitis B virus and hepatitis $C$ virus after antiviral treatment with pegylated interferon-a $2 b$ and ribavirin. Scand J Gastroenterol. 2009;44:1487-90.

4. Soriano V. Reactivation of Hepatitis B in HIV Patients Treated for Hepatitis C. AIDS Rev. 2016;18:222-3.

5. Hawkins C, Grant J, Ammerman LR, Palella F, Mclaughlin M, Green R, et al. High rates of hepatitis $\mathrm{C}$ virus ( $\mathrm{HCV}$ ) cure using direct-acting antivirals in HIV/HCV-coinfected patients: a real-world perspective. J Antimicrob Chemother. 2016:71:2642-5.

6. Collins JM, Raphael KL, Terry C, Cartwright EJ, Pillai A, Anania FA, et al. Hepatitis B Virus Reactivation During Successful Treatment of Hepatitis C Virus With Sofosbuvir and Simeprevir. Clin Infect Dis. 2015;61:1304-6.

7. De Monte A, Courjon J, Anty R, Cua E, Naqvi A, Mondain V, et al. Directacting antiviral treatment in adults infected with hepatitis $C$ virus: Reactivation of hepatitis B virus coinfection as a further challenge. J Clin Virol. 2016;78:27-30.

8. Hayashi K, Ishigami M, Ishizu Y, Kuzuya T, Honda T, Nishimura D, et al. A case of acute hepatitis B in a chronic hepatitis C patient after daclatasvir and asunaprevir combination therapy: hepatitis B virus reactivation or acute self-limited hepatitis? Clin J Gastroenterol. 2016:9:252-6.

9. Takayama H, Sato T, Ikeda F, Fujiki S. Reactivation of hepatitis B virus during interferon-free therapy with daclatasvir and asunaprevir in patient with hepatitis B virus/hepatitis C virus co-infection. Hepatol Res. 2016;46:489-91.

10. Ende AR, Kim NH, Yeh MM, Harper J, Landis CS. Fulminant hepatitis B reactivation leading to liver transplantation in a patient with chronic hepatitis $C$ treated with simeprevir and sofosbuvir: a case report. J Med Case Rep. 2015;9:164.

11. FDA Drug Safety Communication: FDA warns about the risk of hepatitis B reactivating in some patients treated with direct-acting antivirals for hepatitis. https://www.fda.gov/Drugs/DrugSafety/ucm522932.htm. Accessed 10 Apr 2016.

12. Sulkowski MS, Chuang WL, Kao JH, Yang JC, Gao B, Brainard DM, et al. No Evidence of Reactivation of Hepatitis B Virus Among Patients Treated With Ledipasvir-Sofosbuvir for Hepatitis C Virus Infection. Clin Infect Dis. 2016:63:1202-4

13. Gane EJ, Hyland RH, An D, Svarovskaia ES, Brainard D, McHutchison JG. Ledipasvir and sofosbuvir for HCV infection in patients coinfected with HBV. Antivir Ther. 2016;21:605-9.

14. Kaloyannidis P, Batsis I, Yannaki E, et al. Allografted recipients immunized against hepatitis $B$ virus are at high risk of gradual surface antibody (HbsAb) disappearance post transplant, regardless of adoptive immunity transfer. Biol Blood Marrow Transplant. 2007;13:1049-56.

15. Sagnelli E, Coppola N, Marrocco C, Onofrio M, Sagnelli C, Coviello G, et al. Hepatitis C virus superinfection in hepatitis B virus chronic carriers: a reciprocal viral interaction and a variable clinical course. J Clin Virol. 2006:35:317-20

16. Sagnelli E, Coppola N, Pisaturo M, Masiello A, Tonziello G, Sagnelli C, et al. HBV superinfection in $\mathrm{HCV}$ chronic carriers: a disease that is frequently severe but associated with the eradication of HCV. Hepatology. 2009;49:1090-7.

17. Chen SY, Kao CF, Chen CM, Shih CM, Hsu MJ, Chao CH, et al. Mechanisms for inhibition of hepatitis $B$ virus gene expression and replication by hepatitis C virus core protein. J Biol Chem. 2003;278:591-607.

18. Schüttler CG, Fiedler N, Schmidt K, Repp R, Gerlich WH, Schaefer S. Suppression of hepatitis $B$ virus enhancer 1 and 2 by hepatitis $C$ virus core protein. J Hepatol. 2002:37:855-62.

19. Pasquinelli C, Shoenberger JM, Chung J, Chang KM, Guidotti LG, Selby M, et al. Hepatitis $C$ virus core and $E 2$ protein expression in transgenic mice. Hepatology. 1997;25:719-27. 
20. Guo H, Zhou T, Jiang D, Cuconati A, Xiao GH, Block TM, et al. Regulation of hepatitis B virus replication by the phosphatidylinositol 3-kinase-akt signal transduction pathway. J Virol. 2007:81:10072-80.

21. Song K, Han C, Dash S, Balart LA, Wu T. MiR-122 in hepatitis B virus and hepatitis C virus dual infection. World J Hepatol. 2015;7:498-506.

22. Soriano V, Labarga P, de Mendoza C, Peña JM, Fernández-Montero JV, Benítez $L$, et al. Emerging challenges in managing hepatitis $B$ in HIV patients. Curr HIV/AIDS Rep. 2015;12:344-52.

23. Lepelletier C, Salmona M, Berçot B, Maylin S, Sellier PO. First description of past Hepatitis B Virus infection acute reactivation occurring in a Human Immunodeficiency Virus infected patient as manifestation of immune reconstitution inflammatory syndrome. J Infect Chemother. 2016;22:490-4.

24. Coffin CS, Mulrooney-Cousins PM, Osiowy C, van der Meer F, Nishikawa S, Michalak TI, et al. Virological characteristics of occult hepatitis B virus in a North American cohort of human immunodeficiency virus type 1-positive patients on dual active anti-HBV/HIV therapy. J Clin Virol. 2014;60:347-53.

Submit your next manuscript to BioMed Central and we will help you at every step:

- We accept pre-submission inquiries

- Our selector tool helps you to find the most relevant journal

- We provide round the clock customer support

- Convenient online submission

- Thorough peer review

- Inclusion in PubMed and all major indexing services

- Maximum visibility for your research

Submit your manuscript at www.biomedcentral.com/submit
Biomed Central 